\title{
Experimental Study of Distribution of Partial Discharges in Insulation Impregnated at Different Temperatures
}

\author{
K. Smilli ${ }^{2}$ L. Herous ${ }^{*}, 1$ and M. Nemamcha ${ }^{1}$ \\ ${ }^{1}$ Laboratoire de Génie Electrique de Guelma (LGEG). Université de 8 mai 1945, B.P 401 - 24000, Guelma, Algérie.
}

${ }^{2}$ Université Badji MokhtarBP 12 El-Hadjar 23000 Annaba, Algérie.

Received 24 July 2012; Accepted 29 November 2012

\begin{abstract}
In the present work we are particularly interested in the effects of low temperature on partial discharges in all film capacitors models plan/plan made of impregnated polypropylene (pp) and fed with a high alternating voltage.

The experimental study has confirmed the existence of two regimes of discharges with a second regime conduct to the breakdown of the capacitor. These regimes are characterized by a difference in the number of discharges and a different distribution of the apparent charge.
\end{abstract}

Keywords: Partial Discharge, Breakdown, Polypropylene, Capacitors, Mixed Dielectrics, Jarylec.

\section{Introduction}

In the solid insulating or mixed partial discharges are often precursors of dielectric breakdown. The electrical discharge is a phenomenon that occurs when the electric field exceeds the dielectric strength of the material. It results in partial or complete degradation of the insulating material. Various studies have been conducted to understand its evolution [16]. In our previous studies, we studied the evolution of partial discharges at low temperatures as a function of voltage application, the change in frequency as a function of voltage and temperature [7]. In this work, the focus of a share in the distribution of the number of partial discharges in the insulating material and also the evolution of apparent charges depending on the temperature. The work done on the evolution of discharges in different ambient temperatures have clearly shown that increasing the temperature in a volume of the dielectric leads to a reduction of the threshold electric field required for the admission of partial discharges

\section{Experimental techniques}

The detection and measurement of partial discharge was carried out with a device manufactured at LEMD Grenoble [8]. This device uses the electrical and optical expressions of partial discharge.

It allows making measurement of discharge in the order of $0.05 \mathrm{pC}$ with minimum duration between two successive discharges is $330 \mathrm{~ns}$. The diagram of Figure 1 represents the basic circuit for the electric partial discharge detection.

\footnotetext{
*E-mail address: Iherous@yahoo.fr

ISSN: 1791-2377 @ 2012 Kavala Institute of Technology. All rights reserved.
}

Partial discharge appearance in the study cell causes current flows through the external circuit. The current circulates in the RLC impedance that allows the suppression of low frequency component of the current $i$. The impulses resulting across the impedance have a time constant $\mathrm{RC}=40 \mathrm{~ns}$ (fig.1). When a discharge is detected, its amplitude and its polarity as well as the instant of its appearance are measured. The phase of the discharge appearance is deduced from this instant. The device includes a thermostatic drying-room that reaches temperatures until $-40{ }^{\circ} \mathrm{C}$.

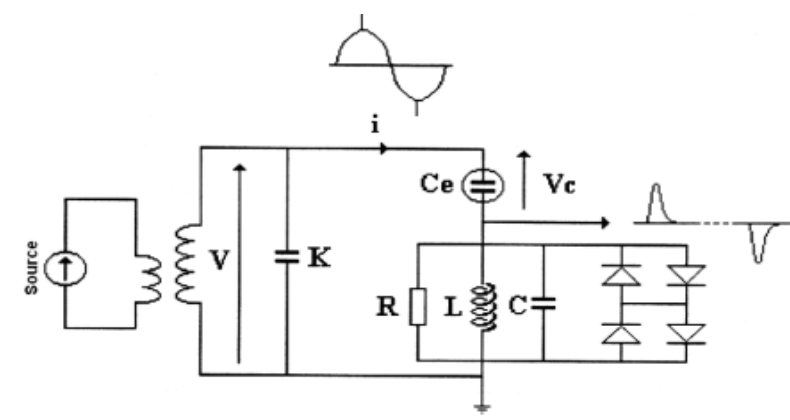

Fig. 1 Principle of partial discharge measurement

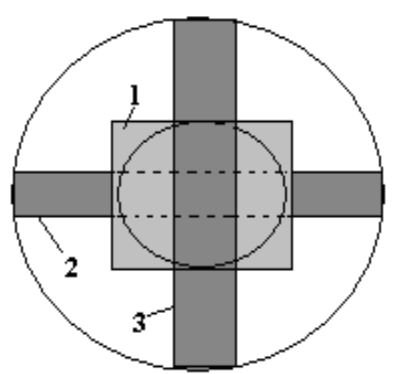

Fig. 2 Study cell, top view 
The study cell (fig.2) is a model for any film impregnated capacitor. It consists of a plastic material (Teflon) in which two aluminium ribbons are disposed at 90 degrees and separated by polypropylene films of $13.6 \mu \mathrm{m}$ thickness [9]. The study cell is filled with a dielectric liquid: the jarylec C100, used in powers capacitors. The Jarylec is a mixture of monobenzyltoluene and dibenzyltoluene, also with traces of tribenzyltoluene.The impregnation's role is to fill any air pockets in the dielectric to avoid the initiation of a partial discharge at relatively low voltage. This type of insulation is used in capacitors for the compensation of reactive energy and therefore the partial discharge evolution, often, constitutes a precursory factor of their dielectric rupture.

\section{Experimental results}

We have presented the distributions of the number $\mathrm{n}(\Phi)$ and amplitude of discharge Qmoy $(\Phi)$ by position in the phase of the alternating voltage for each type of distribution we give a representative example of each discharge regime at different temperatures (figures 2 and 3 ).

Figure 2-a shows the distribution of the number of discharges in the cycle in the first regime were obtained for $\mathrm{U}=6 \mathrm{KV}$. We note that there are almost as many positive discharges than negative discharges. We note also that the width of the distribution of discharge increases with decreasing temperature; it is centered around the maximum voltage and differs from one temperature to another by the peak position. For temperatures were recorded for positive and negative discharges following peaks:

Table 2 Angular position of the maximum distribution of partial discharges for two regimes

\begin{tabular}{c|c|c|c|c}
\hline \multirow{2}{*}{$\mathrm{T}^{\circ} \mathrm{C}$} & \multicolumn{2}{|c|}{ Peaks of 1st regime } & \multicolumn{2}{c}{ Peaks of 2nd regime } \\
\cline { 2 - 5 } & + & - & + & - \\
$28^{\circ} \mathrm{C}$ & $78^{\circ}$ & $240^{\circ}$ & $45^{\circ}$ & $132^{\circ}$ \\
$0^{\circ} \mathrm{C}$ & $70^{\circ}$ & $252^{\circ}$ & $30^{\circ}$ & $180^{\circ}$ \\
$-10^{\circ} \mathrm{C}$ & $52^{\circ}$ & $237^{\circ}$ & $10^{\circ}$ & $197^{\circ}$ \\
$-20^{\circ} \mathrm{C}$ & $42^{\circ}$ & $253^{\circ}$ & $58^{\circ}$ & $187^{\circ}$ \\
\hline
\end{tabular}

Figure $2 \mathrm{~b}$ corresponds to the second regime identified discharges. They were produced during the breakdown of the dielectric for different temperatures. There is a wider distribution of discharges resulting in an increase in the number of discharges. We note that the appearance of discharge occurs at the zero crossing of the voltage at $28^{\circ} \mathrm{C}$ temperature distribution has a peak around $45^{\circ}$ for positive discharges and a peak of $132^{\circ}$ for negative discharges. Table 1 shows the rest of the angular distributions of the number of discharges for the entire temperature range studied.

Figure 3 shows the observed distribution of apparent average charge per position developed by partial discharges. It is found that decreasing the temperature, average charge apparent discharge increases and has very high amplitudes located towards the maximum of the voltage wave. In Figure $3 \mathrm{a}$, we see that positive discharges are characterized by a broad distribution which increases by decreasing temperature, this confirms what was observed with the distribution of the number of discharges. Landfills have negative charges of the order of PC with the presence of a number of discharges characterized by a relatively high intensity. The amplitudes of positive and negative discharges for the two regimes shown in Table 2 .
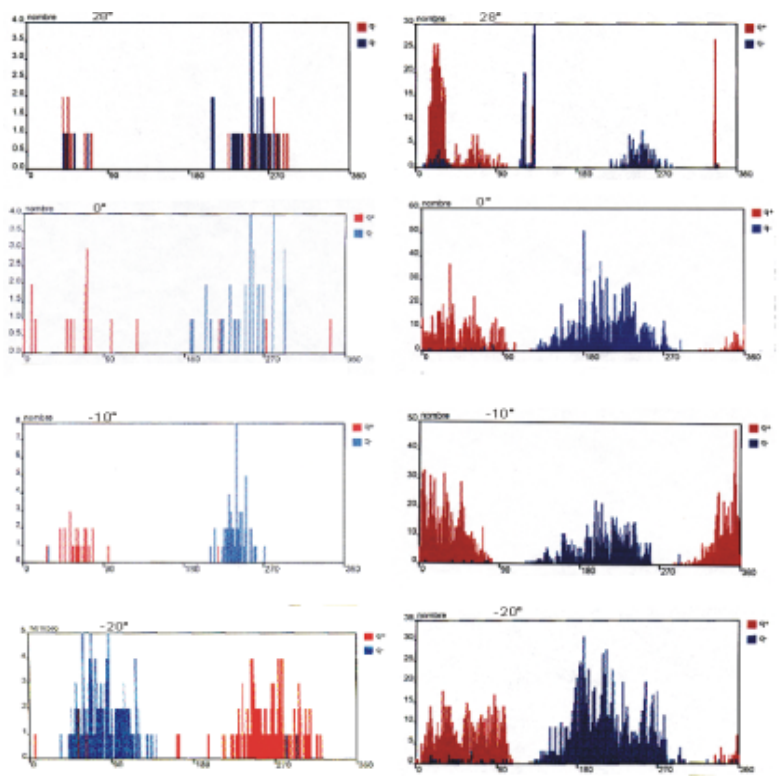

a) 1 st regime

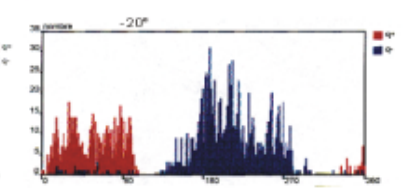

b) 2nd regime

Fig 2. Distribution of a number of discharges per position according to the phase at different temperature

Table 2 the maximum charge on the 1 st and 2 nd regime at different temperatures

\begin{tabular}{c|c|c|c|c}
\multirow{2}{*}{$\mathrm{T}^{\circ} \mathrm{C}$} & \multicolumn{2}{|c|}{ 1st regime } & \multicolumn{2}{c}{ 2nd regime } \\
\cline { 2 - 5 } $28^{\circ} \mathrm{C}$ & $\mathrm{Q}+(\mathrm{PC})$ & $\mathrm{Q}-(\mathrm{PC})$ & $\mathrm{Q}+(\mathrm{PC})$ & $\mathrm{Q}-(\mathrm{PC})$ \\
$0^{\circ} \mathrm{C}$ & 4.47 & 30.89 & 257.36 & 256.86 \\
$-10^{\circ} \mathrm{C}$ & 2,49 & 2,49 & 29,56 & 29,51 \\
$-20^{\circ} \mathrm{C}$ & 7.71 & 7.69 & 45.03 & 44.95 \\
\hline
\end{tabular}

In the second regime Fig. $3 \mathrm{~b}$, the discharges are more intense and more numerous. Note also the broadening of distributions. Discharges have an average intensity of about ten PC at low temperature and several hundred PC at ambiance temperature.
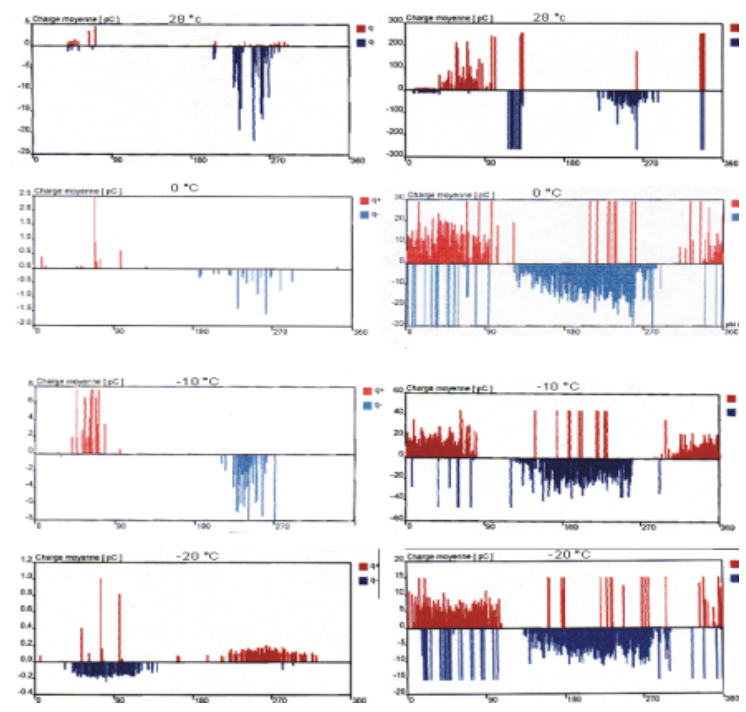

a) 1 st regime

b) 2 nd regime

Fig 3: Distribution of the apparent charge average per position as function to the phase at different temperatures 


\section{Conclusion}

Our results confirm the existence of two regimes of discharges for different temperatures. They show that in $90 \%$ of cases, the second regime conduct to the breakdown of the dielectric.

Discharges of the first regime can be explained by electronic avalanches in the dielectric liquid, followed by formation of bubbles of gas. When the liquid near the reinforcement is saturated with gas, it is a second regime. The latter is characterized by discharges occurring in cavities of gas, we get a regular diet with greater mobility to arrive at the breakdown.

The distribution of the number of discharges in the two regime shows that there are many positive and negative discharges for different temperatures. By decreasing the temperature, we note that the width of the distribution of discharges thus increasing the probability of occurrence of partial discharges increases which allows you to save a larger number of partial discharges with decreasing temperature. In conclusion, low temperatures favor the breakdown of the dielectric.

\section{Acknowledgement}

The experimental work has been performed at LEMD CNRS Grenoble and supported by the French-Algeria cooperation project CMEP/01 MDU523

\section{References}

1. M. Nemamcha, J. P. Gosse and B. Gosse, "Discharges in All-PP Film Model Capacitors", IEEE. Trans. on Elec. Insul. Vol. 28, No 3, pp. 315-323, (1993).

2. H. Suzuki, K. Aihara, T. Okamoto, "Complex Behaviour of a Simple Partial Discharge Model", A Letters Journal Exploring the Frontiers of Physics, Vol. 66, No 1, pp. 28-34, (2004).

3. C. G. Karagiannopoulos, "A Model For Dielectrics Experiencing Partial Discharges Under High Electrics Fields", Journal of Electrostatics, Vol. 65, No 8, pp. 535-541, (2007).

4. M. Nemamcha, J. P. Gosse and B. Gosse, "Effect of Partial Discharges on Impregnated Polypropylene Films", IEEE. Trans. on Dielec. and Elec. Insul. Vol. 1, No 4, pp. 578-584, (1994).

5. R .Hammal, P. Rain, J. P. Gosse and C. Hantouche, "Characterisation of Partial Discharge in Impregnated Capacitor", in Proc. 12th Int. Conf. on Conduction and Breakdown in Dielectric Liquids, pp. 171-174, (Rome), (1996).

6. M. Pompili, C. Mazzeti, "Partial Discharge Behavior in Switchingsurge-aged oil-paper Capacitor Bushing Insulation", IEEE. Trans. on Dielec. and Elec. Insul., Vol. 9, No 1, pp. 104-111, (2002).

7. M.Nemamcha, L.Herous, M. Remadnia, M. Kachi, P.Rain, J.P.Gosse "Partial discharge in capacitor model at low temperature" Journal of Engineering Science and Technology Review 2 (1), pp.137-140, (2009).

8. M. Nemamcha, J. P. Gosse and C. Marteau, "Monitoring of Partial Discharge in Capacitor Models with Impregnated Polypropylene Films ", in Proc. 4th. Int. Conf. on Conduction and Breakdown in Solid Dielectrics, pp. 205-208, (Italy), (1992). 